\title{
Relationship Between Dewfall Time and Shadow Soil Moisture
}

\author{
Xiangang Wen ${ }^{1,4}$, , Yuhua Xie ${ }^{1}$, Chunbo Zhang ${ }^{2}$, Xiaohu $\mathrm{Pu}^{3}$, Shuqing $\mathrm{Ma}^{4}$, Jingyu $\mathrm{Li}^{1}$ \\ ${ }^{1}$ Longyan Xinluo Meteorological Service, Longyan, Fujian, China \\ ${ }^{2}$ Beijing Meteorological Service, Bejing, China \\ ${ }^{3}$ Chongqing Meteorological Information and Technology Support Center, Chongqing, China \\ ${ }^{4}$ China Meteorological Administration Meteorological Observation Center, Beijing, China
}

Email address:

wxgfjly@sina.com (Xiangang Wen)

${ }^{*}$ Corresponding author

To cite this article:

Xiangang Wen, Yuhua Xie, Chunbo Zhang, Xiaohu Pu, Shuqing Ma, Jingyu Li. Relationship Between Dewfall Time and Shadow Soil Moisture. Hydrology. Vol. 7, No. 1, 2019, pp. 10-14. doi: 10.11648/j.hyd.20190701.12

Received: February 11, 2019; Accepted: March 26, 2019; Published: April 18, 2019

\begin{abstract}
The automated Weather Phenomenon Observation System can observe condensation and record the occurring time of weather phenomena by using image identification technology. The time of condensation occurring and the data of soil moisture in the shallow soil layer are analyzed, and the inverse relationship between dewfall time and shadow soil moisture is confirmed by using the data of the automatic present weather observation system and soil moisture observation equipment installed at Pinggu Station in Beijing from April to September in 2011. The condensation phenomenon appears earlier when the soil moisture of 0 to $10 \mathrm{~cm}$ layer is higher. On the contrary, the condensation phenomenon appears later when the soil moisture of 1 to $10 \mathrm{~cm}$ layer is too low. It can be used to predict soil moisture by exploring the timing of dewfall via the automated Weather Phenomenon Observation System, which is useful to monitor drought.
\end{abstract}

Keywords: Dewfall Time, Shallow Layer, Soil Moisture

\section{Introduction}

Dew is water in the form of droplets that appears on the ground and near ground objects due to condensation [1]. The formation of dew is closely related with the near-ground atmosphere and soil moisture. Soil moisture is one of the most important control factors in agricultural production and also the main limiting factor in plant survival [2], restricting the dissolution, transfer and absorption of nutrients and the activity of microorganism in soil, having the significant impact on soil productivity; furthermore, soil moisture condition is the comprehensive reflection of atmosphere, vegetation, terrain, soil factor, and other natural conditions, having the important effect on precipitation runoff, evapotranspiration (vegetation transpiration and soil evaporation). Soil moisture, which is called soil water content, is the quantity of water contained in soil [3]. Soil moisture is one of important physical properties for earth-air interaction [4]. Although some researchers have done some investigations on the relationship between the distribution of soil moisture and climate [5-13], there is little research on the relationship between condensation time and shallow soil moisture. In this article, earth condensation automation observation can explore the relationship betweenthe starting time of dewfall and soil moistureby analyzing the relationship of dewfall time and the moisture in the shallow soil layer, find out the certain relationship between dewfall time and soil moisture. Therefore, researching on the formation of condensation and soil moisture and discovering dewfall time and the change of soil moisture is meaningful for real-time service and theoretical research on agricultural production.

\section{Source and Observation Mechanism}

The meteorological data in this article comes from:

(1) The data from automation observation of rainfall in Pinggu, Huairou, Mentougou, Chaoyang, Daxing, Shunyi, 
and Yanqing stations of Beijing from April to September 2011.

(2) The upload data from automation observation of soil moisture at Pinggu National Weather Station from April to September 2011. Pinggu National Weather Station was using Shanghai Changwang ASWI-1 Automatic Soil Moisture Observatory. It gathers soil moisture sensor utilize of FDR [14] principal and bus data acquisition technology. The product specifications of this sensor meets the China Meteorological Administration (CMA) soil moisture observation requirements. Its measuring depth generally will cover $0-10 \mathrm{~cm}, 10-20 \mathrm{~cm}, 20-30 \mathrm{~cm}$, $30-40 \mathrm{~cm}, 40-50 \mathrm{~cm}, 50-60 \mathrm{~cm}, 60-70 \mathrm{~cm}, 70-80 \mathrm{~cm}$ and $90-100 \mathrm{~cm} 8$ layers. The system displays real-time data and the hour of relative humidity, volumetric water content, gravimetric moisture content, water storage and generates a standard file automatically [3]. For analysis convenience, this article uses the shadow layer $0-10 \mathrm{~cm}$ relative humidity of soil as soil moisture for analysis. We treated the average relative humidity of soil as daily average relative humidity of soil.

The relative soil moisture: percentage of gravimetric moisture content over field water storage.

$$
R=\frac{w}{f_{c}} \times 100 \%
$$

$R$ : soil relative soil moisture (\%), recorded as integer;

$W$ : gravimetric moisture content $(\%)$;

$f_{c}$ : field water storage.

(3) The condensation data from automation observation in Pinggu, Huairou, Mentougou, Chaoyang, Daxing, Shunyi, and Yanqing stations of Beijing from April to September 2011.

The automated Weather Phenomenon Observation System [15], using water droplets that are condensed on the ground and near ground objects, having distinguished color visual characteristics, automatically identifies the appearance and records its time. The automated Condensation Observation device is made up of CCD image sensor, dew collector and processor. The dew collector has 3-layer frosted glass carrier chips: 3-layer carrier chips are fixed by specific supports, with the heights from the earth surface $5 \mathrm{~cm}, 3 \mathrm{~cm}$, and $1 \mathrm{~cm}$ respectively; each carrier chip has the transparent and frosted glass area, whose frosted glass area is facing down; In the absence of condensation, due to obvious difference of brightness, the boundary between the transparent and frosted glass area can be distinguished clearly; once the condensation happens, the boundary between the transparent and frosted glass area is blurred and the corresponding image brightness changes a lot. CCD image sensor acquires the images of carrier chips and the sends the images to the processor. Then the processor calculates the difference of normalized brightness's and change information of the transparent and frosted glass area for 3-layer carrier chips individually. This way it can identify the happening of condensation [16].

The formula to calculate the difference of normalized brightness is:

$$
R=500 \times \frac{R_{1}-R_{2}}{R_{1}+R_{2}}
$$

$R:$ the difference of normalized brightness's;

$R_{1}$ : the brightness of frosted glass area;

$R_{2}$ : the brightness of transparent glass area.

We can judge whether the condensation happens though its speed under the following rules: 1. The continuous 3-piece normalized difference decreases and the decreasing of the normalized difference between the neighboring pieces exceeds the threshold value of 10 ; and 2 . The decreasing of continuous 2-piece normalized difference exceeds the threshold value of 20 . If both conditions meet, dewfall happens.

From the data in Table 1, $0-10 \mathrm{~cm}$ soil moisture is divided into five segments: $100 \%-90 \%, 90 \%-80 \%, 80 \%-70 \%, 70 \%$ $60 \%, 60 \%$. We analyzed the corresponding average dewfall time for each segment. Figure 1 shows the relationship between average dewfall time and $0-10 \mathrm{~cm}$ soil average moisture, with $y$-axis showing and $0-10 \mathrm{~cm}$ soil average moisture and $\mathrm{x}$-axis showing the dewfall time (after time exchange said earlier). Figure 1 clearly illustrates that the larger $0-10 \mathrm{~cm}$ soil moisture is, the earlier happens the condensation; conversely, the smaller $0-10 \mathrm{~cm}$ soil moisture is, the later happens the condensation. In addition, when 0-10 $\mathrm{cm}$ soil moisture is less than certain value, the condensation won't happen at all.

\section{Statistics Analysis of the Relationship Between Soil Moisture and Dewfall}

We collected dewfall time and $1-10 \mathrm{~cm}$ soil average relative moisture during condensation from the automated Weather Phenomenon Observation System at Pinggu station between April and September 2011. For convenience of calculation, exchange dewfall time via this: regard noon 12:00 as zero hour, and the noon at the second day as 23:59. For example, if condensation happens at Beijing time 21:00, it is recorded as 9:00; if at Beijing time 02:00, it is recorded at 14:00. At Pinggu station, the automated Weather Phenomenon Observation System observes 126 days' condensation between April and September 2011, shown in Table 1. From the table 1, when $0-10 \mathrm{~cm}$ soil average moisture is relatively high $(>80 \%)$, condensation happens more before 08:00, and it happens less after 08:00. When 0$10 \mathrm{~cm}$ soil average moisture decreases gradually, condensation happens with less chance before 08:00 and with more chance after 08:00. Condensation happens most when $0-10 \mathrm{~cm}$ soil average moisture is $90 \%-100 \%$. When $0-10 \mathrm{~cm}$ soil average moisture decreases gradually, condensation happens less gradually. 
Table 1. 0-10 cm Soil average relative moisture and dewfall times at Pinggu station.

\begin{tabular}{llllll}
\hline \multirow{2}{*}{ Soil relative moisture (\%) } & dewfall times & & & & \\
\cline { 2 - 6 } & $\mathbf{t} \leq \mathbf{8}$ & $\mathbf{8}<\mathbf{t} \leqq \mathbf{1 0}$ & $\mathbf{1 0}<\mathbf{t} \leq \mathbf{1 2}$ & $\mathbf{t} \mathbf{1 2}$ & total \\
\hline $90-100$ & 31 & 8 & 1 & 0 & 40 \\
$80-90$ & 18 & 4 & 4 & 8 & 34 \\
$70-80$ & 8 & 10 & 5 & 5 & 28 \\
$60-70$ & 0 & 2 & 1 & 6 & 14 \\
$<60$ & 0 & 1 & 3 & 6 & 10 \\
\hline
\end{tabular}

Notes: $\mathrm{t}$ is the time of dewfall after time exchanging.

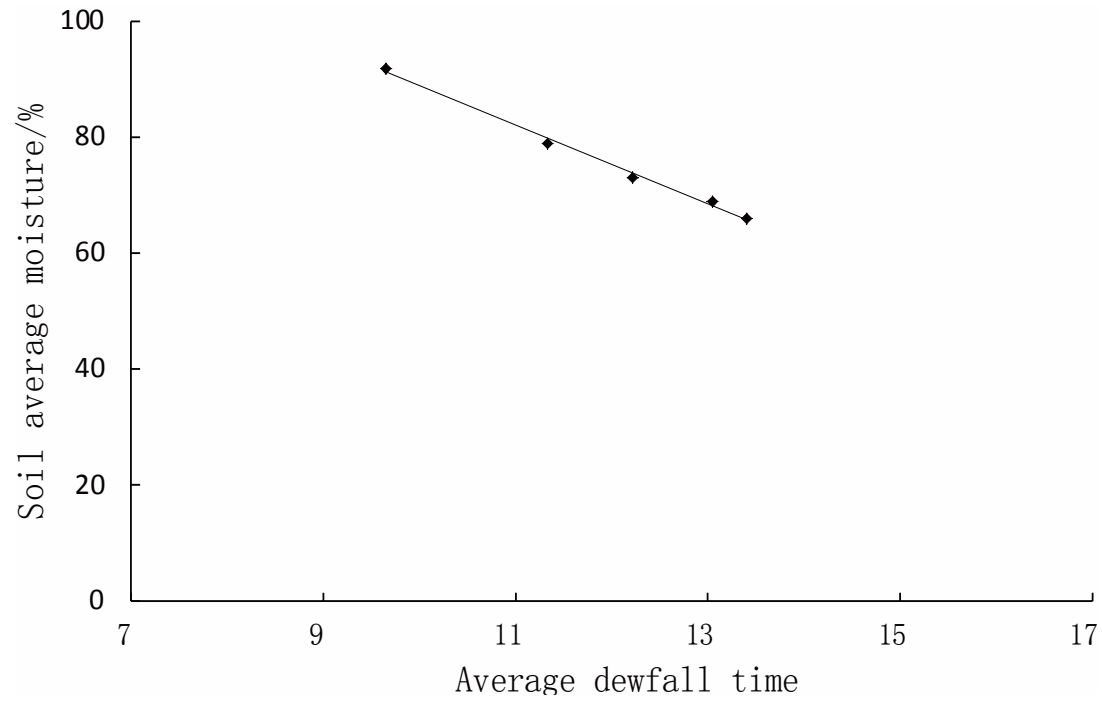

Figure 1. The relationship between average dewfall time and $0-10 \mathrm{~cm}$ soil average moisture.

\section{Dewfall and Other Main Meteorological Factors}

Table 2 lists dewfall time and its corresponding $0-10 \mathrm{~cm}$ soil average relative moisture, precipitation, 2 min wind speed and lawn temperature, and dew temperature difference. From Table 2, precipitation happened on May 8th-9th, and 0-10cm soil average relative moisture is the highest, reaching $100 \%$. With the extension of precipitation time, $0-10 \mathrm{~cm}$ soil average relative moisture reduces, and the daily dewfall time gets later gradually correspondingly.

Table 2. Dewfall time and its corresponding 0-10cm soil average relative moisture at Pinggu station on May 8-20, 2011.

\begin{tabular}{|c|c|c|c|c|c|}
\hline Date & Precipitation & Dewfall Time & $\begin{array}{l}0-10 \mathrm{~cm} \text { Soil } \\
\text { Relative Moisture }\end{array}$ & $\begin{array}{l}\text { Average } 2 \text { min wind } \\
\text { speed at the dewfall day }\end{array}$ & $\begin{array}{l}\text { The difference of grass temperature } \\
\text { and dew temperature }\end{array}$ \\
\hline $5 / 8$ & 6.2 & Precipitate & 100 & 2.6 & \\
\hline $5 / 9$ & 3.7 & Precipitate & 96 & 1.4 & \\
\hline $5 / 10$ & & $9: 12$ & 90 & 1.9 & 0.5 \\
\hline $5 / 11$ & & $9: 39$ & 90 & 1.3 & -1.6 \\
\hline $5 / 12$ & & No dew & 83 & 4.3 & \\
\hline $5 / 13$ & & $11: 20$ & 79 & 1.0 & 0.2 \\
\hline $5 / 14$ & & $12: 13$ & 73 & 0.4 & 0.2 \\
\hline $5 / 15$ & & $13: 13$ & 69 & 1.0 & -0.4 \\
\hline $5 / 16$ & & $13: 24$ & 67 & 0.6 & -1.4 \\
\hline $5 / 17$ & & No dew & 64 & 2.4 & \\
\hline $5 / 18$ & & No dew & 63 & 2.7 & \\
\hline $5 / 19$ & & No dew & 62 & 2.7 & \\
\hline $5 / 20$ & & No dew & 60 & 1.8 & \\
\hline
\end{tabular}

In terms of meteorology, the best meteorological condition for dew formation is at the clear breezy night. The clear night is beneficial for ground or the ground objects to radioactively cool down fast; breeze circulates the air near the ground, which sends in the fresh air on the ground and near ground objects, and at the same time takes away the air after vapor condensing. This way it can have enough vapors for condensation [17]. On
May 12th, the dewfall didn't happen and average 2-min wind speed was $4.3 \mathrm{~m} / \mathrm{s}$. Although the condensation didn't happen on May 12th, the relationship between dewfall time and 0-10 $\mathrm{cm}$ soil average relative moisture is good as follows.

The grass temperature and dew temperature during condensation have the difference. The difference is from -1.6 to 0.5 from May 8th to May 20th, 2018. 


\section{Relationship Between Dewfall Time and the Days After Precipitation}

The larger $0-10 \mathrm{~cm}$ soil moisture is, the earlier happens condensation; conversely, the smaller $0-10 \mathrm{~cm}$ soil moisture is, the later happens condensation. Does this conclusion apply to other stations? The automated Weather Phenomenon Observation System was set up in Pinggu, Huairou, Mentougou, Chaoyang, Daxing, Shunyi, and Yanqing stations but Soil moisture observation system was only set up in Pinggu station. Other stations didn't have that system so they didn't have hourly soil moisture data. Below we used indirect way to verify our conclusion. First, analyze the relationship between the condensation and the days after precipitation. Then use the relationship between the soil moisture and the days after precipitation to verify the relationship between condensation and soil moisture. The term "the days after precipitation" means the number of days after last precipitation.

Table 3 and Table 4 show the recording data for precipitation and dewfall time after precipitation at different stations between June 2011 and August 2011.

Table 3. Precipitation and dewfall time after precipitation at five stations (Huarou, Mentougou, Chaoyang, Daxing, and Yanqing stations) on June 24-30, 2011.

\begin{tabular}{|c|c|c|c|c|c|c|c|c|c|c|}
\hline & Huarou & & Mentougou & & Chaoyang & & Daxing & & Yanqing & \\
\hline & $\begin{array}{l}\text { Daily } \\
\text { precipitation }\end{array}$ & $\begin{array}{l}\text { Dewfall } \\
\text { time }\end{array}$ & $\begin{array}{l}\text { Daily } \\
\text { precipitation }\end{array}$ & $\begin{array}{l}\text { Dewfall } \\
\text { time }\end{array}$ & $\begin{array}{l}\text { Daily } \\
\text { precipitation }\end{array}$ & $\begin{array}{l}\text { Dewfall } \\
\text { time }\end{array}$ & $\begin{array}{l}\text { Daily } \\
\text { precipitation }\end{array}$ & $\begin{array}{l}\text { Dewfall } \\
\text { time }\end{array}$ & $\begin{array}{l}\text { Daily } \\
\text { precipitation }\end{array}$ & $\begin{array}{l}\text { Dewfall } \\
\text { time }\end{array}$ \\
\hline $6 / 24$ & 13.9 & & 24.5 & & 6.8 & & 23.43 .4 & & 26.2 & \\
\hline $6 / 25$ & & $20: 44$ & & $20: 13$ & & $20: 02$ & & $22: 02$ & & $21: 06$ \\
\hline $6 / 26$ & & $20: 53$ & & $20: 21$ & & $20: 21$ & & $22: 21$ & & $21: 15$ \\
\hline $6 / 27$ & & $21: 33$ & & $20: 30$ & & $20: 39$ & & $23: 00$ & & $22: 54$ \\
\hline $6 / 28$ & & $22: 21$ & & $21: 43$ & & $22: 29$ & & $23: 19$ & & $22: 53$ \\
\hline $6 / 30$ & 15.2 & & 12.3 & & 11.4 & & 0.7 & & 17.3 & \\
\hline
\end{tabular}

Table 4. Precipitation and dewfall time after precipitation at three stations (Huarou, Shunyi, Mentougou stations) on July 7-15, 2011.

\begin{tabular}{|c|c|c|c|c|c|c|}
\hline & \multicolumn{2}{|l|}{ Huarou } & \multicolumn{2}{|l|}{ Shunyi } & \multicolumn{2}{|l|}{ Mentougou } \\
\hline & Daily precipitation & Dewfall time & Daily precipitation & Dewfall time & Daily precipitation & Dewfall time \\
\hline $7 / 7$ & 17.9 & & 25.4 & & 6.1 & \\
\hline $7 / 8$ & 0.9 & & & $19: 51$ & & $20: 00$ \\
\hline $7 / 9$ & & $21: 02$ & & $20: 19$ & & $20: 49$ \\
\hline $7 / 10$ & & $22: 06$ & & $20: 31$ & & $22: 58$ \\
\hline $7 / 11$ & & $22: 28$ & & $20: 41$ & & $23: 17$ \\
\hline $7 / 12$ & 4.3 & & & $22: 40$ & & \\
\hline $7 / 14$ & & $21: 18$ & 8.7 & & & $0: 33$ \\
\hline $7 / 15$ & 20.5 & & 3.3 & & 35.3 & \\
\hline
\end{tabular}

From Table 3 and Table 4, we can conclude: after precipitation, dewfall time is gradually pushed back with the decreasing days after precipitation. For example, after precipitation in Huarou station on June 24th-30th, dewfall time is $20: 44$ and then afterwards dewfall time has been constantly pushed back in the continuous days until June 29th, whose dewfall time is 23:40.

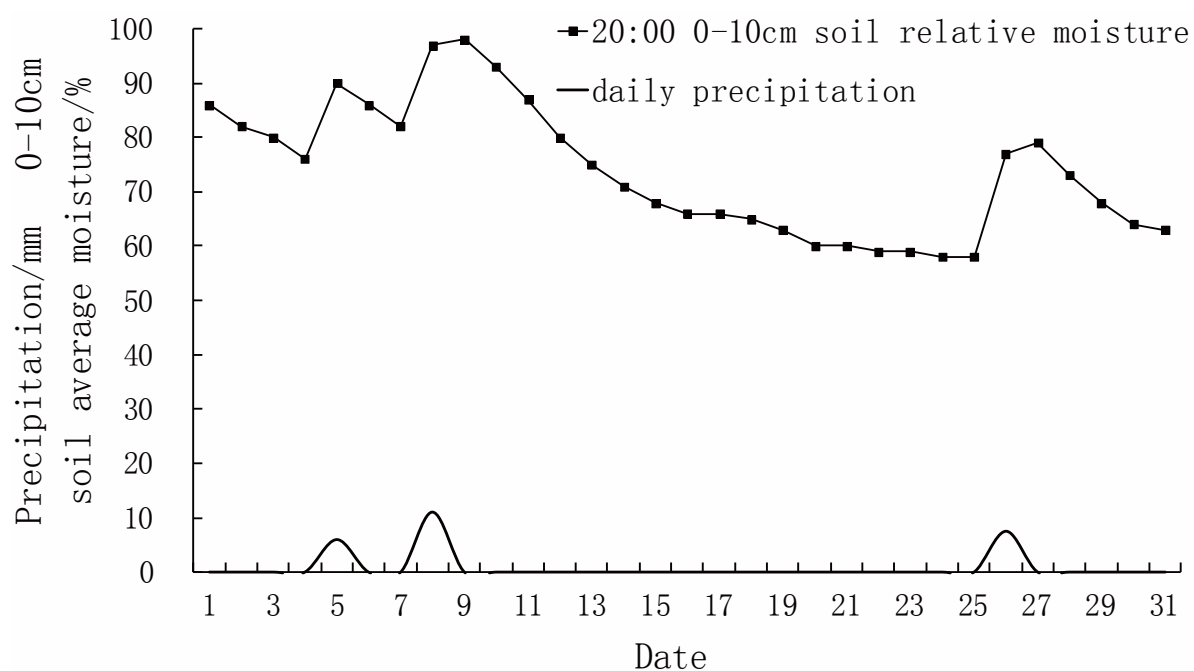

Figure 2. The relationship between the precipitation and daily 0-10 cm soil relative moisture at 20:00 at Pinggu station in May 2011. 
Some expertshave made some research towards the relationship between the distribution of soil moisture and climate: after precipitation, soil moisture change gets smaller with the increasing days after precipitation. Figure 2 shows the relationship between the precipitation and daily $0-10 \mathrm{~cm}$ soil relative moisture at 20:00 at Pinggu station in May 2011. From Figure 2, soil moisture and daily precipitation are closed related: soil relative moisture is at maximum during precipitation; with the more days after precipitation, the soil relative moisture reduces. According to this pattern, it concludes that the larger $0-10 \mathrm{~cm}$ soil moisture is, the earlier happens condensation; conversely, the smaller $0-10 \mathrm{~cm}$ soil moisture is, the later happens condensation. This conclusion also applies to other stations.

\section{Conclusion}

Byanalyzing shadow soil moisture and dewfall time through the automated Weather Phenomenon Observation System, we conclude that:

(1) There is close relationship between soil moisture and precipitation. The soil moisture has obvious periodic variation characteristics with precipitation process. The soil moisture is at maximum during precipitation. Then the soil moisture is gradually decreasing as the time from the precipitation is delayed.

(2) The relationship between condensation time and soil moisture is more obvious: $0-10 \mathrm{~cm}$ soil humidity is higher, the earlier the condensation. When the soil moisture is small enough, even if other meteorological conditions are set, condensation may not occur.

(3) It is possible to use the weather phenomenon to automatically observe the occurrence of condensation and to predict the soil moisture condition, which had certain application value for monitoring drought.

(4) Due to the fact that the automatic observation condensation has not yet been fully operational in China, there are limitations on the acquisition of condensation time. When most stations have condensation time and soil moisture data, the relationship between the condensation time and shadow soil moisture will be further studied.

\section{Acknowledgements}

This research was supported by non-profit organization, Meteorological research project"Research on Automatic Observation Technology of Weather Phenomena" (GYHY200906032).

\section{References}

[1] China Meteorological Administration, Ground meteorological observation specification [M]. Beijing, Meteorological Publisher, 2003.
[2] Jiangxue Cui, Ground Meteorological Observation [M] Beijing, Meteorological Publisher, 2011.

[3] China Meteorological Administration Integrated Observatory bureau. "Automated Soil Moisture observation specification [S]”, Beijing, China Meteorological Administration, 2010.

[4] Shuwen Zhang, Congiian Qiu, Weidong Zhang. "Variational Method for Estimating Surface Heat Flux and Near-surface Soil Water Content." Journal of Meteorology, 65 (3), 440-449, 2007.

[5] Daren Lu, Zouzhong Chen, Jiayi Chen, etc. "Comprehensive study on soil, vegetation and atmospheric interaction in semiarid grassland of Inner Mongolia.” Journal of Meteorology, 65 (3), 571-593, 2005.

[6] Guofeng Zhu, Hanxiong Pan, Yi Zhang. Spatial and temporal differentiation of relative humidity of cultivated soil in China. Journal of Geographical Science, 2019 (3).

[7] Cheng Zhu, Chunxiang Shi, Lin Xi, etc. "Simulation and Evaluation of Different Depth Soil Moisture in China." Meteorological Technology, 41 (3), 529-536, 2013.

[8] Hongwei Zhang, Huailiang Chen, Zhongyang Liu. "Construction and Application of Enhanced Soil Surface Moisture Content Index Model Based on MODIS Data." Meteorological Technology, 40 (6), 1039-1043, 2012.

[9] Bo Li, Niao Zhang, Shihao Tang. Variation characteristics of soil moisture at different time scales based on network observation. Journal of Meteorology, 2018 (6): 1040-1052.

[10] Hongnan Jiang, Analysis of the Influence Factors and Influence of Temporal and Spatial Changes of Soil Moisture in Oasis in Arid Areas.” Jiangsu Agricultural Science. 2018, 46 (20): 194-299.

[11] Changyong Dai, ZhiyanZuo. "Relationship between the Climates in Earlier Winter and Spring in Easter China." Meteorological Technology, 38 (3), 300-305, 2010.

[12] Jingyu Pa, Xiaoying Shi, Shuqiu Yu. "Preliminary Study on the Change of Soil Moisture in the East of Northwest Region." Meteorological Technology, 31 (4), 226-230, 2003.

[13] Hongnan Jiang, Hongtao Jiang, Jianli Ding. Temporal and spatial variation of soil moisture in Yutian Oasis based on remote sensing data and its influencing factors. Arid Area Resources and Environemnt. 2017 (12): 139-145.

[14] Feilong Huang, Xingti Li, Hongzhi Huang, etc."Soil moisture observatory system and application based on FDR." Meteorology, 38 (6), 764-768, 2012.

[15] Shuqing Ma, Kequn Wu, Dongdong Chen, etc. "Automated Weather Phenomenon Observation System Design." Meteorology, 37 (9), 1166-1172, 2011.

[16] XiaoxiaLi, ShuqingMa, Kejun Wu, etc. "Automated Dewfall Phenomenon Observation Device Design and Research" Meteorology, 38 (4), 501-507, 2012.

[17] ChengduMeteorological college. Meteorology. Beijing: Agriculture Publisher, 1979. 